\title{
Novel Poly(esterimide)s Containing a Push-Pull Type Azobenzene Moiety-Synthesis, Characterization and Optical Properties
}

\author{
By Mariola SIWY, ${ }^{1}$ Bozena JARZABEK,${ }^{1}$ Krzysztof SWITKOWSKI, ${ }^{2}$ \\ Bronislaw PURA, ${ }^{2}$ and Ewa SCHAB-BALCERZAK ${ }^{1, *}$
}

In this paper, novel poly(esterimide)s with attached as a side group azobenzene chromophores are presented. The polymers differing in substituents on the azobenzene moieties and chromophore concentration. Azopolymers were obtained by a twostep synthetic approach. This include the preparation of a precursor poly(esterimide) with benzene moiety pendant from main chains, followed by the covalent bonding of the NLO chromophores onto the polyimide backbone by a post-azo-coupling reaction using the following coupling components: $p$-nitroaniline, 2-cyan-4-nitroanilin, 2,4-dinitroaniline and Disperse Orange 3. The precursor poly(esterimide) was obtained from synthesized 2,2' $\mathrm{N}$-phenylethyloaniline-di(4-estro-1,2dicarboxylic)] anhydride and 4,4'-methylene bis(2,6-dimethylaniline).

The degree of functionalization of the poly(esterimide)s was estimated by UV-vis spectroscopy. The obtained polymers were characterized and evaluated by FT-IR, ${ }^{1} \mathrm{H}$ NMR, X-ray, UV-vis, DSC and TGA. The results showed the azopolymers exhibited high glass transition temperatures $\left(T_{\mathrm{g}}=159-224^{\circ} \mathrm{C}\right)$, high thermal stability with decomposition temperatures in the range of $311-334^{\circ} \mathrm{C}$ and good solubilities in common organic solvents. First time two-photon absorption (TPA) coefficient in cast films of amorphous azopoly(esterimide)s was measured using Z-scan experiment which was performed with femtosecond laser pulses $100 \mathrm{fs}$ at $800 \mathrm{~nm}$. The TPA coefficient was determined to be in the range of 1.54-11.69 $\mathrm{cm} / \mathrm{GW}$.

KEY WORDS: Polyimides / Azobenzene Chromophores / Two-Photon Absorption / Z-scan /

Nonlinear optical (NLO) organic materials have been extensively investigated because of their broad applications in the area of optoelectronics and photonics. ${ }^{1}$ The development of novel two-photon absorbing (TPA) materials, which can be excited by near-infrared (NIR) light (700-1100 nm), is an area of intensive research. TPA is currently being studied for a variety of three-dimensional (3D) applications, including the microfabrication of structures that cannot be created using standard lithographic techniques, ultrahigh-density holographic data storage, optical power limiters, upconversion lasers, twophoton fluorescence microscopy and photodynamic therapy. ${ }^{2-6}$ TPA process involves the simultaneous absorption of two photons in the presence of an intense laser beam, at wavelengths far from the molecule linear absorption region, whenever the material has an electronic excited level at twice the frequency of the input beam. In the linear absorption process, the absorbed light is directly proportional to the incident intensity, while in TPA the rate of energy absorbed is proportional to the square of the excitation intensity $\left(\mathrm{I}^{2}\right)$. In TPA, virtual excited states are created with photons of half the nominal one-photon excitation energy, which provides better penetration into absorbing media and the $\mathrm{I}^{2}$ dependence of the absorption process allows for high 3D spatial selectivity through the use of a tightly focused laser beam and all processes are localized in the small volume. While this feature is the key to high spatial resolution. ${ }^{6}$ Practical applications involving TPA processes, however, still required materials with large absorption cross-section with large absorption coefficient. To date, various NLO molecules and molecular design rule have been investigated. Variety of donor-conjugated bridgeacceptor (D- $\pi-A)$, donor-conjugated bridge-donor (D- $\pi-D)$, donor-acceptor-donor (D-A-D), acceptor-donor-acceptor (A-DA) derivatives and the role of the $\pi$-center have been studied. ${ }^{7}$ Different compounds as conjugated bridges are employed for example fluorene, biphenyl, naphthyl groups, dithienothiophene, bis(styryl)benzene derivatives ${ }^{6}$ and azoaromatic compounds. ${ }^{8}$ Nowadays, azobenzene containing materials have been the subject of intensive research due to possibility of multiple trans-cis-trans isomerization cycles which opens a direct route to optically change molecular arrangement in nanoscale which is attractive for various applications. ${ }^{9}$ The use of nonresonant excitation to alter the properties of azocontaining materials has been reported recently in the literature. ${ }^{6}$ Survey of the literature reveals that generally, twophoton induced phenomena were investigated in polymer films doped with various azocompounds. Two-photon induced optical storage capability of poly(methylmethacrylate) (PMMA) doped with organometallic azoaromatic compounds, ${ }^{10}$ doped with Disperse Red 13 (DR1), ${ }^{11}$ with 2-(3,5dichloro-2-pyridine azo)-5-diethylamino phenol, ${ }^{12}$ with 1-(2pyridylazo)-2-naphthol, ${ }^{13}$ with Disperse Red 13 (DR13) ${ }^{14}$ were studied. Two-photon induced anisotropy in PMMA doped with Disperse Orange 3 (DO13) ${ }^{15}$ was investigated as well. The host-guest system, even though the most convenient for

\footnotetext{
${ }^{1}$ Centre of Polymer and Carbon Materials, Polish Academy of Sciences, 34 M. Curie-Sklodowska Str., Zabrze 41-819, Poland

${ }^{2}$ Faculty of Physics, Warsaw University of Technology, 75 Koszykowa Str., Warsaw 00-662, Poland

*To whom correspondence should be addressed (Tel: +48-32-273-2214, Fax: +48-32-271-2969, E-mail: eschab-balcerzak@cmpw-pan.edu.pl).
} 
preparation, has some disadvantages such as low solubility of the chromophores in the polymer matrix, phase separation of guest and host, migration or sometimes evaporation of NLO molecules from the films. ${ }^{16}$ To avoid those limitations NLO chromophores can be attached covalently to a polymer chain. Not so many articles report two-photon properties of undoped polymers, i.e., two-photon absorption coefficient was measured in a 4-(dialkylamino) $4^{\prime}$-nitrostilbene) (DANS) side-chain polymer film, ${ }^{17}$ in $\pi$-conjugated polymers ${ }^{18}$ for example in poly $(p$ phenylenevinylene) film, ${ }^{19}$ and in solution of copolymers with triphenylamine in the main chain. ${ }^{20}$ However, there is a lack of two-photon effect investigations in polymer films containing covalently bonded azobenzene derivatives into polymer backbone. To the best of our knowledge, nonlinear absorption was measured only in solution of poly(aryl ether) containing azo chromophores as a side group. ${ }^{21}$

Among the various azobenzene polymer systems developed, functionalized aromatic polyimides are promising optically active materials in device applications because of their high thermal stability, high glass transition temperature and optical transparency. ${ }^{22,23}$ Azobenzene chromophores have been incorporated into polymer structures in a variety of configurations by a number of different synthetic approaches. ${ }^{9}$ One of them is a direct polycondesation of the chromophore containing monomers. Another one involves the postfunctionalization, which allows chromophores to be introduced into reactive precursor polymers without exposure of the chromophores to aggressive polymerization conditions. ${ }^{24}$ In this method, because of mild conditions, there are no restrictions for the kind of chromophore to be incorporated into the polymer structure. The various postfunctionalization reactions were developed. Two of them are the most utilize, i.e., Mitsunobu condensation between hydroxy group in polyimides and alkyl hydroxyl groups of the chromophores ${ }^{25,26}$ and postazo-coupling reaction between polymer and diazonium salts. $^{27,28}$

In this article, coupling reaction was applied to obtain azobenzene functionalized poly(esterimide)s differing in the degree of functionalization and the kind of the chromophores. The objective of this work is focused on synthesis, characterization and measurements of the TPA coefficient of poly(esterimide)s containing azobenzene units as side groups. The polymers were designed and synthesized specifically for this work. The polymer main chain contains ester linkages and aliphatic groups, which led to the solubility being enhanced. The chromophores in synthesized polymers form D- $\pi$-A type of molecule. In the chromophores, the two benzene rings and the azo bond provide the conjugated $\pi$-system, the ethylenoamino group acts as electron donor and nitro-, two nitro- or nitro- and cyano-groups acts as electron acceptor. To increase in length of the conjugation bridge azobenzene derivative that possess two azo bonds between three benzene rings were introduced into polymer chain as well. Here, for the first time to our knowledge, the preliminary measurements of TPA coefficient were carried out in a azobenzene side-chain polyimides films.

\section{EXPERIMENTAL}

\section{Materials}

$\mathrm{N}$-Methyl-2-pyrrolidone (NMP), $\mathrm{N}, \mathrm{N}$-dimethylformamide (DMF), pyridine (Py), chloro(trimethyl)silane (CTMS), 4nitroaniline, 2,4-dinitroaniline, 2-cyan-4-nitroaniline, 4-aminobenzonitrile, Disperse Orange 3 and 4,4'methylenebis(2,6dimethylaniline) and $\mathrm{N}, \mathrm{N}$-di-(2-hydroxyethyl)aniline were purchased from Aldrich Chemical Co. and were used without purification. 2,2'-\{4-[(4-Nitrophenyl-azo $\}$ phenyl]iminobis(ethyl benzene-1,2-dicarboxylic acid anhydride-4-carboxylate) (DARed19) was synthesized and characterized in our previous work. $^{29}$

\section{Synthesis of Chromophores AZ-1-AZ-4}

Chromophore 4-Nitro-4' ${ }^{\prime}$-(N,N-dihydroxyethyl)aminoazobenzene. (AZ-1) (Disperse Red 19) was synthesized according to the published procedure. ${ }^{30}$

AZ-1: ${ }^{1} \mathrm{H}$ NMR (DMSO- $\left.d_{6}, \delta, \mathrm{ppm}\right): 3.59\left(\mathrm{t}, \mathrm{CH}_{2}, 4 \mathrm{H}\right), 3.62(\mathrm{t}$, $\left.\mathrm{CH}_{2}, 4 \mathrm{H}\right), 4.86(\mathrm{t}, \mathrm{OH}, 2 \mathrm{H}), 6.90(\mathrm{~d}, 2 \mathrm{H}), 7.81(\mathrm{~d}, 2 \mathrm{H}), 7.92(\mathrm{~d}$, 2H), 8.35 (d, 2H). FT/IR (KBr, cm $\left.{ }^{-1}\right): 3272(\mathrm{OH}), 2988,2920$ $\left(\mathrm{CH}_{2}\right), 1512\left(\mathrm{NO}_{2}\right)$. UV-vis (NMP): $\lambda_{\max }=290,509 \mathrm{~nm}$ $\left(\varepsilon_{509}=8.98 \times 10^{4} \mathrm{Lmol}^{-1} \mathrm{~cm}^{-1}\right)$, m.p. $=195^{\circ} \mathrm{C}$ (Lit. m.p. $\left.198-200{ }^{\circ} \mathrm{C},{ }^{30} 207.8-209.3^{26}\right)$. Yield: $80 \%$.

Chromophore 2,4-Dinitro-4' $-(N, N$-dihydroxyethyl)aminoazobenzene. (AZ-2) was prepared according to the modified method. ${ }^{31}$

To 2,4-dinitroaniline $(1.83 \mathrm{~g}, 10 \mathrm{mmol})$ a solution of hydrochloric acid $(36 \%, 2.8 \mathrm{~mL})$ was added and the mixture was stirred and heated to $60-70{ }^{\circ} \mathrm{C}$. Into the resulting warm solution $20 \mathrm{~mL}$ of water and $30 \mathrm{~mL}$ of acetic acid $(99.5 \%$,) was added. The reaction mixture was stirred overnight. Afterward, the flask was cooled down in ice bath to $0-5{ }^{\circ} \mathrm{C}$ and the solution of sodium nitrite $(0.84 \mathrm{~g}, 12 \mathrm{mmol})$ in $2 \mathrm{~mL}$ of water was added dropwise under stirring. After stirring for $1.5 \mathrm{~h}$, acetic acid $(5 \mathrm{~mL}, 99.5 \%)$ was added and the mixture was stirred for $1 \mathrm{~h}$ in an ice bath. Then to the diazonium salt solution $\mathrm{N}, \mathrm{N}$-di-(2hydroxyethyl)aniline $(1.868 \mathrm{~g}, 11 \mathrm{mmol})$ dissolved in $2 \mathrm{~mL}$ of methanol was added dropwise and the mixture was stirred for $0.5 \mathrm{~h}$ under cooling, followed by neutralization ( $\mathrm{pH} 5-6)$ with anhydrous sodium acetate $(10 \mathrm{~g}, 120 \mathrm{mmol})$ and was stirred for $2 \mathrm{~h}$ more and the reaction mixture was kept overnight in a refrigerator. Then the solution was poured into water and precipitate formed was collected and was washed with plenty of water and with methanol and dried.

AZ-2: ${ }^{1} \mathrm{H}$ NMR (DMSO- $\left.d_{6}, \delta, \mathrm{ppm}\right): 3.61\left(\mathrm{t}, \mathrm{CH}_{2}, 4 \mathrm{H}\right), 3.63(\mathrm{t}$, $\left.\mathrm{CH}_{2}, 4 \mathrm{H}\right), 4.89(\mathrm{t}, \mathrm{OH}, 2 \mathrm{H}), 6.92(\mathrm{~d}, 2 \mathrm{H}), 7.83(\mathrm{~d}, 2 \mathrm{H}), 7.90(\mathrm{~d}$, $1 \mathrm{H}), 8.50(\mathrm{q}, 1 \mathrm{H}), 8.88(\mathrm{~d}, 1 \mathrm{H})$. FT/IR $\left(\mathrm{KBr}, \mathrm{cm}^{-1}\right): 3377$ (OH), 2993, $2888\left(\mathrm{CH}_{2}\right), 1514\left(\mathrm{NO}_{2}\right)$. UV-vis (NMP): $\lambda_{\max }=$ $289,535 \mathrm{~nm}\left(\varepsilon_{535}=3.01 \times 10^{4} \mathrm{Lmol}^{-1} \mathrm{~cm}^{-1}\right)$, m.p. $=161^{\circ} \mathrm{C}$. Yield: $35 \%$.

Chomophore 2-Cyano-4-nitro-4'-(,$N$-dihydroxyethyl)aminoazobenzene. (AZ-3) was prepared from 2-cyan-4-nitroaniline via the same procedure as described for synthesis of AZ-2.

AZ-3: ${ }^{1} \mathrm{H}$ NMR (DMSO- $\left.d_{6}, \delta, \mathrm{ppm}\right): 3.63\left(\mathrm{t}, \mathrm{CH}_{2}, 4 \mathrm{H}\right), 3.78$ 
(t, $\left.\mathrm{CH}_{2}, 4 \mathrm{H}\right), 5.02(\mathrm{t}, \mathrm{OH}, 2 \mathrm{H}), 6.97(\mathrm{~d}, 2 \mathrm{H}), 7.86(\mathrm{~d}, 2 \mathrm{H}), 7.97$ $(\mathrm{d}, 1 \mathrm{H}), 8.52(\mathrm{q}, 1 \mathrm{H}), 8.89(\mathrm{~d}, 1 \mathrm{H}) . \mathrm{FT} / \mathrm{IR}\left(\mathrm{KBr}, \mathrm{cm}^{-1}\right)$ : $3335(\mathrm{OH}), 2952,2887\left(\mathrm{CH}_{2}\right), 2233(\mathrm{CN}), 1525,1343\left(\mathrm{NO}_{2}\right)$. UV-vis $\quad(\mathrm{NMP}): \quad \lambda_{\max }=290, \quad 548 \mathrm{~nm} \quad\left(\varepsilon_{548}=2.21 \times 10^{4}\right.$ $\left.\mathrm{Lmol}^{-1} \mathrm{~cm}^{-1}\right)$, m.p. $=155^{\circ} \mathrm{C}$. Yield: $43 \%$.

Chomophore 4-Nitro-4'-(,$N$-dihydroxyethyl)amino-bisazobenzene. (AZ-4) was synthesized according to the published procedure. $^{30}$

AZ-4: ${ }^{1} \mathrm{H}$ NMR (DMSO- $\left.d_{6}, \delta, \mathrm{ppm}\right): 3.60\left(\mathrm{t}, \mathrm{CH}_{2}, 4 \mathrm{H}\right), 3.63$ $\left(\mathrm{t}, \mathrm{CH}_{2}, 4 \mathrm{H}\right), 4.85(\mathrm{t}, \mathrm{OH}, 2 \mathrm{H}), 6.88(\mathrm{~d}, 2 \mathrm{H}), 7.79(\mathrm{~d}, 2 \mathrm{H})$, 7.95-8.10 (m, 6H), $8.42(\mathrm{~d}, 2 \mathrm{H})$. FT/IR $\left(\mathrm{KBr}, \mathrm{cm}^{-1}\right): 3301$ $(\mathrm{OH}), 1515\left(\mathrm{NO}_{2}\right), 2960,2894\left(\mathrm{CH}_{2}\right)$. UV-vis (NMP): $\left.\lambda_{\max }=349,530 \mathrm{~nm} \varepsilon_{530}=3.44 \times 10^{4} \mathrm{Lmol}^{-1} \mathrm{~cm}^{-1}\right)$, m.p. $=$ $248{ }^{\circ} \mathrm{C}$. Yield: $76 \%$.

Synthesis of $2,2^{\prime}[N$-Phenylethyloaniline-di(4-estro-1,2-dicarboxylic)]anhydride DA. Dianhydride (DA) was synthesized from trimellictic anhydride acid chloride and $N, N^{\prime}$-(di-2hydroxyethyl)aniline in a way similar to dianhydrides described previously. ${ }^{32}$

DA: ${ }^{1} \mathrm{H}$ NMR (DMSO- $\left.d_{6}, \delta, \mathrm{ppm}\right): 3.87\left(\mathrm{t}, \mathrm{CH}_{2}, 2 \mathrm{H}\right), 4.52$ (t, $\left.\mathrm{CH}_{2}, 2 \mathrm{H}\right), 6.62$ (t, 1H), 6.93 (dd, 2H), 7.16 (d, 2H), 8.16 (dd, $2 \mathrm{H}), 8.33(\mathrm{~d}, 2 \mathrm{H}), 8.39$ (d, 2H). FT/IR $\left(\mathrm{KBr}, \mathrm{cm}^{-1}\right): 1854$, 1814, 1780, ( $\mathrm{O}=\mathrm{C}$ in anhydride), 1722 (-O-CO- ester), 2996, $2962\left(\mathrm{CH}_{2}\right)$. UV-vis (NMP): $\lambda_{\max }=266,296 \mathrm{~nm}$, m.p. $171^{\circ} \mathrm{C}$ (Lit. m.p. $198-199^{\circ} \mathrm{C}^{33}$ ). Yield: $38 \%$.

\section{Synthesis of Parent Poly(esterimide) PI}

In order to examine the best polycondesation conditions to obtain polymer with the highest reduced viscosity polycondesation under two standard synthetic routes, i.e., low temperature polycondesation with chemical imidization (1) and high temperature polycondesation (2) and polycondesation under the in situ silylated diamines (3) were carried out.

(1) Low temperature polycondesation with chemical imidization carried out according to the modified procedure. ${ }^{27,34}$

To 4,4'-methylenebis(2,6-dimethylaniline) $(0.51 \mathrm{~g}, 2 \mathrm{mmol})$ in $8.88 \mathrm{~mL}$ NMP dianhydride DA $(1.06 \mathrm{~g}, 2 \mathrm{mmol})$ was added slowly and mixture was stirring at room temperature in an argon atmosphere for $24 \mathrm{~h}$. The resultant poly(amic acid) was imidized with a mixture of acetic anhydride and triethyl amine (diamine-acetic anhydride-triethyl amine $=4: 36: 9$ in mol ratio) at $25^{\circ} \mathrm{C}$ for $48 \mathrm{~h}$. The polyimide was precipitated in a mixture of methanol $(50 \mathrm{~mL})$ and water $(50 \mathrm{~mL})$ and was purified by extraction with methanol in Soxhlet apparatus for $72 \mathrm{~h}$ and then dried at $100{ }^{\circ} \mathrm{C}$ in vacuum. The reduced viscosity $\left(\eta_{\text {red }}\right)$ of polymer was $0.26 \mathrm{dl} / \mathrm{g}$.

(2) High temperature polycondesation.

Dianhydride DA (1.06 g, $2 \mathrm{mmol})$ and 4,4'-methylenebis(2,6dimethylaniline) $(0.51 \mathrm{~g}, 2 \mathrm{mmol})$ in $5 \mathrm{~mL}$ NMP were stirring until dissolve the substrates. Then $1,2 \mathrm{~mL}$ of dichlorobenzene was added to the solution as co-solvent to remove the water formed during the imidization process. The solution was heated at $170{ }^{\circ} \mathrm{C}$ for $4 \mathrm{~h}$ under argon atmosphere. The resultant polyimide was precipitated with methanol and was purified by extraction with methanol in Soxhlet apparatus for $72 \mathrm{~h}$ and then dried at $100{ }^{\circ} \mathrm{C}$ in vacuum. The reduced viscosity $\left(\eta_{\text {red }}\right)$ of polymer was $0.14 \mathrm{dl} / \mathrm{g}$.

(3) Polycondesation under the in situ silylated diamines was carried out as described in the ref 35 .

4,4'-Methylenebis(2,6-dimethylaniline) $(0.51 \mathrm{~g}, 2 \mathrm{mmol})$ in $1.4 \mathrm{~mL}$ NMP was stirred at room temperature under argon atmosphere until all solid had dissolved. Then the required amount of CTMS (0.51 mL, $4 \mathrm{mmol})$ and Py $(0.32 \mathrm{~mL}, 4 \mathrm{mmol})$ were slowly added, and the solution were stirred for $15 \mathrm{~min}$ to ensure the formation the silylated diamine. After this time, the solution was cooled to $0{ }^{\circ} \mathrm{C}$, and dianhydride DA (1.06 g, $2 \mathrm{mmol}$ ) was rapidly added followed by $2 \mathrm{~mL}$ of NMP. The reaction mixture was stirred for $15 \mathrm{~min}$ at $0{ }^{\circ} \mathrm{C}$ and then the temperature was raised up to room temperature and left overnight. Acetic anhydride $(1.13 \mathrm{~mL}, 12 \mathrm{mmol})$ and pyridine $(0.64 \mathrm{~mL}, 8 \mathrm{mmol})$ were then added to promote imidization and the reaction mixture was stirred at room temperature for $6 \mathrm{~h}$ followed by heating for a further hour at $60^{\circ} \mathrm{C}$. The resultant polymer was precipitated with water, washed several times with water and purified by extraction with methanol in Soxhlet apparatus for $72 \mathrm{~h}$ and then dried at $100^{\circ} \mathrm{C}$ in vacuum. The reduced viscosity $\left(\eta_{\text {red }}\right)$ of polymer was $0.35 \mathrm{dl} / \mathrm{g}$.

PI: ${ }^{1} \mathrm{H}$ NMR (DMSO- $d_{6}, \delta$, ppm): $2.01\left(\mathrm{~s}, \mathrm{CH}_{3}, 12 \mathrm{H}\right), 3.87$ (m, $\left.\mathrm{CH}_{2}, 6 \mathrm{H}\right), 4.51$ (t, $\left.\mathrm{CH}_{2}, 4 \mathrm{H}\right), 6.59$ (t, 1H), 6.91 (d, 2H), 7.12 (t, 2H), 8.01 (s, 4H), 8.26-8.32 (m, 6H). FT/IR $\left(\mathrm{KBr}, \mathrm{cm}^{-1}\right)$ : 1782, $1723(\mathrm{C}=\mathrm{O}$ in imide), 1372, $732(\mathrm{C}-\mathrm{N}), 2957,2923$ $\left(\mathrm{CH}_{2}\right) . \mathrm{UV}$-vis (NMP): $\lambda_{\max }=263,307 \mathrm{~nm}$.

\section{Synthesis of Azobenzene Functionalized Poly(esterimide)s} PI-1-PI-4

Synthesis of Azobenzene Functionalized Poly(esterimie) PI1a. Polymer PI-1a was prepared from DARed19 and 4,4' methylenebis(2,6-dimethylaniline) via the same procedure as described for synthesis of PI by method (3).

PI-1a: ${ }^{1} \mathrm{H}$ NMR (DMSO- $\left.d_{6}, \delta, \mathrm{ppm}\right): 1.97$ (s, $\left.\mathrm{CH}_{3}, 12 \mathrm{H}\right), 3.88$ (t, $\left.\mathrm{CH}_{2}, 4 \mathrm{H}\right), 4.05\left(\mathrm{~s}, \mathrm{CH}_{2}, 2 \mathrm{H}\right), 4.61\left(\mathrm{t}, \mathrm{CH}_{2}, 4 \mathrm{H}\right), 6.93(\mathrm{~d}, 2 \mathrm{H})$ $7.09(\mathrm{t}, 2 \mathrm{H}), 7.78-7.90(\mathrm{~m}, 4 \mathrm{H}), 8.01(\mathrm{~s}, 4 \mathrm{H}), 8.20-8.40(\mathrm{~m}$, $6 \mathrm{H})$. FT/IR $\left(\mathrm{KBr}, \mathrm{cm}^{-1}\right)$ : 1782, $1724(\mathrm{C}=\mathrm{O}$ in imide), 1373, $732(\mathrm{C}-\mathrm{N}), 1515,1340\left(\mathrm{NO}_{2}\right), 2959,2924\left(\mathrm{CH}_{2}\right)$. UV-vis (NMP): $\lambda_{\max }=261,311,484 \mathrm{~nm}\left(\varepsilon_{484}=3.24 \times 10^{4} \mathrm{Lmol}^{-1}\right.$ $\left.\mathrm{cm}^{-1}\right)$.

Synthesis of Azobenzene Functionalized Poly(esterimide) PI-

1b. Polymer PI-1b was obtained according to the published procedure. $^{33}$

A solution of hydrochloric acid $(36 \%, 0.31 \mathrm{~mL})$ was added slowly to $p$-nitroaniline $(0.14 \mathrm{~g}, 1.03 \mathrm{mmol})$ in water $(0.31 \mathrm{~mL})$ and stirred at room temperature. Then the solution was cooled down to $0-5{ }^{\circ} \mathrm{C}$ and sodium nitrite $(0.08 \mathrm{~g}, 1.13 \mathrm{mmol})$ in $0.29 \mathrm{~mL}$ of water was added dropwise. The prepared diazonium salt solution was added dropwise into cooled PI (0.75 g, $1 \mathrm{mmol})$ dissolved in NMP $(4.17 \mathrm{~mL})$. The mixture was stirred for $5 \mathrm{~h}$ and then precipitated into the mixture of methanol $(20 \mathrm{~mL})$ and water $(20 \mathrm{~mL})$. The polyimide was purified by extraction with methanol in Soxhlet apparatus for $72 \mathrm{~h}$ and then dried at $100{ }^{\circ} \mathrm{C}$ in vacuum.

PI-1b: ${ }^{1} \mathrm{H}$ NMR (DMSO- $\left.d_{6}, \delta, \mathrm{ppm}\right): 2.00\left(\mathrm{~s}, \mathrm{CH}_{3}, 24 \mathrm{H}\right), 3.87$ (t, $\left.\mathrm{CH}_{2}, 8 \mathrm{H}\right), 4.07\left(\mathrm{~s}, \mathrm{CH}_{2}, 4 \mathrm{H}\right), 4.52\left(\mathrm{t}, \mathrm{CH}_{2}, 8 \mathrm{H}\right), 6.59$ (t, $\left.1 \mathrm{H}\right)$, 
$6.92(\mathrm{~d}, 4 \mathrm{H}), 7.13(\mathrm{t}, 4 \mathrm{H}), 7.78-7.86(\mathrm{~m}, 4 \mathrm{H}), 8.02(\mathrm{~s}, 8 \mathrm{H})$, 8.20-8.40 (m, 12H). FT/IR $\left(\mathrm{KBr}, \mathrm{cm}^{-1}\right): 1782,1723(\mathrm{C}=\mathrm{O}$ in imide), 1374, 732 (C-N), 1515, $1341\left(\mathrm{NO}_{2}\right), 2958,2923\left(\mathrm{CH}_{2}\right)$. UV-vis (NMP): $\lambda_{\max }=266,298,483 \mathrm{~nm}$.

Synthesis of Azobenzene Functionalized Poly(esterimie) PI1c. Polymer PI-1c was prepared in a method similar to PI-1b but the order of addition of diazonium salt solution into polymer solution was changed, i.e., in this case the polymer PI solution was added by dropwise to diazonium salt solution.

PI-1c: ${ }^{1} \mathrm{H}$ NMR (DMSO- $\left.d_{6}, \delta, \mathrm{ppm}\right): 2.00\left(\mathrm{~s}, \mathrm{CH}_{3}, 24 \mathrm{H}\right), 3.86$ (t, $\left.\mathrm{CH}_{2}, 8 \mathrm{H}\right), 4.06\left(\mathrm{~s}, \mathrm{CH}_{2}, 4 \mathrm{H}\right), 4.51\left(\mathrm{t}, \mathrm{CH}_{2}, 8 \mathrm{H}\right), 6.59(\mathrm{t}, 1 \mathrm{H})$, $6.92(\mathrm{~d}, 4 \mathrm{H}), 7.12(\mathrm{t}, 4 \mathrm{H}), 7.77-7.85(\mathrm{~m}, 4 \mathrm{H}), 8.01(\mathrm{~s}, 8 \mathrm{H})$, 8.20-8.40 (m, 12H). FT/IR $\left(\mathrm{KBr}, \mathrm{cm}^{-1}\right): 1782,1724(\mathrm{C}=\mathrm{O}$ in imide), 1371, 731 (C-N), 1515, $1340\left(\mathrm{NO}_{2}\right), 2955,2922\left(\mathrm{CH}_{2}\right)$. UV-vis (NMP): $\lambda_{\max }=264,290,480 \mathrm{~nm}$.

Synthesis of Azobenzene Functionalized Poly(esterimie)s PI-1d and PI-1e. Polymers PI-1d and PI-1e was prepared according to ref 36 .

Sodium nitrite $(0.07 \mathrm{~g}, 1 \mathrm{mmol})$ was added slowly to concentrated sulfuric acid $(2.5 \mathrm{~mL})$ and mixture was heated to $70{ }^{\circ} \mathrm{C}$ under stirring. Sodium nitrite dissolved slowly and a solution of nitrosyl sulfuric acid was formed. After the solution was cooled to $5{ }^{\circ} \mathrm{C} p$-nitroaniline $(0.14 \mathrm{~g}, 1 \mathrm{mmol})$ was added and mixture was stirred at $5^{\circ} \mathrm{C}$ for $40 \mathrm{~min}$. The solution of PI $(0.64 \mathrm{~g}$, $0.85 \mathrm{mmol}$ ) in $16 \mathrm{~mL}$ of DMF to the prepared diazonium salt solution was added dropwise. Then the solution was kept in a refrigerator overnight. The precipitate formed in reaction mixture was filtered off (PI-1d). The filtrate was poured into water and additional part of polymer (PI-1e) was obtained. The polymers were washed repeatedly with water until a neutral stage was achieved and further purified by Soxhlet apparatus with methanol for $72 \mathrm{~h}$ and then dried at $100^{\circ} \mathrm{C}$ in vacuum.

PI-1d: ${ }^{1} \mathrm{H}$ NMR (DMSO- $\left.d_{6}, \delta, \mathrm{ppm}\right): 1.97$ (s, $\left.\mathrm{CH}_{3}, 24 \mathrm{H}\right), 3.88$ (t, $\left.\mathrm{CH}_{2}, 8 \mathrm{H}\right), 4.07\left(\mathrm{~s}, \mathrm{CH}_{2}, 4 \mathrm{H}\right), 4.61\left(\mathrm{t}, \mathrm{CH}_{2}, 8 \mathrm{H}\right), 6.59(\mathrm{t}, 1 \mathrm{H})$, $6.98(\mathrm{~d}, 4 \mathrm{H}), 7.10(\mathrm{t}, 4 \mathrm{H}), 7.80-7.95(\mathrm{~m}, 4 \mathrm{H}), 8.01(\mathrm{~s}, 8 \mathrm{H})$, 8.20-8.40 (m, 12H). FT/IR $\left(\mathrm{KBr}, \mathrm{cm}^{-1}\right): 1781,1722(\mathrm{C}=\mathrm{O}$ in imide), 1372, 731 (C-N), 1514, $1340\left(\mathrm{NO}_{2}\right), 2955,2922\left(\mathrm{CH}_{2}\right)$. UV-vis (NMP): $\lambda_{\max }=261,481 \mathrm{~nm}$.

\section{Synthesis of Azobenzene Functionalized Poly(esterimide)s PI-2, PI-3 and PI-4}

Polymers PI-2, PI-3 and PI-4 were prepared in a way similar to PI-1d and PI-1e by using different coupling components: 2,4-dinitroaniline, 2-cyan-4-nitroaniline and Disperse Orange 3 , respectively.

PI-2a: ${ }^{1} \mathrm{H}$ NMR (DMSO- $\left.d_{6}, \delta, \mathrm{ppm}\right): 1.97$ (s, $\left.\mathrm{CH}_{3}, 24 \mathrm{H}\right), 3.86$ (t, $\left.\mathrm{CH}_{2}, 8 \mathrm{H}\right), 4.08\left(\mathrm{~s}, \mathrm{CH}_{2}, 4 \mathrm{H}\right), 4.62\left(\mathrm{t}, \mathrm{CH}_{2}, 8 \mathrm{H}\right), 6.58(\mathrm{t}, 1 \mathrm{H})$, $6.92(\mathrm{~d}, 4 \mathrm{H}), 7.09(\mathrm{t}, 4 \mathrm{H}), 7.76(\mathrm{~d}, 1 \mathrm{H}), 8.00(\mathrm{~d}, 1 \mathrm{H}), 8.28(\mathrm{~d}$, $1 \mathrm{H}), 8.42(\mathrm{~d}, 8 \mathrm{H}), 8.75-8.85(\mathrm{~m}, 12 \mathrm{H})$. FT/IR $\left(\mathrm{KBr}, \mathrm{cm}^{-1}\right)$ : 1782, $1722(\mathrm{C}=\mathrm{O}$ in imide), 1371, $730(\mathrm{C}-\mathrm{N}), 1340,1514$ $\left(\mathrm{NO}_{2}\right), 2955,2920\left(\mathrm{CH}_{2}\right)$. UV-vis (NMP): $\lambda_{\max }=295,518 \mathrm{~nm}$. PI-2b: ${ }^{1} \mathrm{H}$ NMR (DMSO- $\left.d_{6}, \delta, \mathrm{ppm}\right): 1.98\left(\mathrm{~s}, \mathrm{CH}_{3}, 12 \mathrm{H}\right), 3.89$ (t, $\left.\mathrm{CH}_{2}, 4 \mathrm{H}\right), 4.10\left(\mathrm{~s}, \mathrm{CH}_{2}, 2 \mathrm{H}\right), 4.63\left(\mathrm{t}, \mathrm{CH}_{2}, 4 \mathrm{H}\right), 6.93(\mathrm{~d}, 2 \mathrm{H})$, $7.10(\mathrm{t}, 2 \mathrm{H}), 7.78(\mathrm{~d}, \pm 1 \mathrm{H}), 8.03(\mathrm{~d}, 1 \mathrm{H}), 8.33(\mathrm{~d}, 1 \mathrm{H}), 8.43(\mathrm{~d}$, $4 \mathrm{H}), 8.80-8.90(\mathrm{~m}, 6 \mathrm{H})$. FT/IR $\left(\mathrm{KBr}, \mathrm{cm}^{-1}\right): 1781,1723$ $\left(\mathrm{C}=\mathrm{O}\right.$ in imide), 1370, $730(\mathrm{C}-\mathrm{N}), 1340,1514\left(\mathrm{NO}_{2}\right), 2954$,
$2922\left(\mathrm{CH}_{2}\right)$. UV-vis (NMP): $\lambda_{\max }=261,297,517 \mathrm{~nm}\left(\varepsilon_{517}=\right.$ $\left.3.28 \times 10^{4} \mathrm{Lmol}^{-1} \mathrm{~cm}^{-1}\right)$.

PI-3a: ${ }^{1} \mathrm{H}$ NMR (DMSO- $\left.d_{6}, \delta, \mathrm{ppm}\right): 1.97$ (s, $\left.\mathrm{CH}_{3}, 24 \mathrm{H}\right), 3.86$ (t, $\left.\mathrm{CH}_{2}, 8 \mathrm{H}\right), 4.11\left(\mathrm{~s}, \mathrm{CH}_{2}, 4 \mathrm{H}\right), 4.63$ (t, $\left.\mathrm{CH}_{2}, 8 \mathrm{H}\right), 6.59$ (t, $\left.1 \mathrm{H}\right)$, $6.92(\mathrm{~d}, 4 \mathrm{H}), 7.08(\mathrm{t}, 4 \mathrm{H}), 7.85(\mathrm{~d}, 1 \mathrm{H}), 8.01(\mathrm{~d}, 1 \mathrm{H}), 8.29(\mathrm{~d}$, $1 \mathrm{H}), 8.45(\mathrm{~s}, 8 \mathrm{H}), 8.70-8.80(\mathrm{~m}, 12 \mathrm{H})$. FT/IR $\left(\mathrm{KBr}, \mathrm{cm}^{-1}\right)$ : $2233(\mathrm{CN}), 1782,1723(\mathrm{C}=\mathrm{O}$ in imide), 1372, $731(\mathrm{C}-\mathrm{N})$, 1514, $1343\left(\mathrm{NO}_{2}\right), 2921,2959\left(\mathrm{CH}_{2}\right)$. UV-vis (NMP): $\lambda_{\max }=$ 292, $526 \mathrm{~nm}$.

PI-3b: ${ }^{1} \mathrm{H}$ NMR (DMSO- $\left.d_{6}, \delta, \mathrm{ppm}\right): 1.98\left(\mathrm{~s}, \mathrm{CH}_{3}, 12 \mathrm{H}\right), 3.88$ (t, $\left.\mathrm{CH}_{2}, 4 \mathrm{H}\right), 4.12$ (s, $\left.\mathrm{CH}_{2}, 2 \mathrm{H}\right), 4.64\left(\mathrm{t}, \mathrm{CH}_{2}, 4 \mathrm{H}\right), 6.92(\mathrm{~d}, 2 \mathrm{H})$, $7.09(\mathrm{t}, 2 \mathrm{H}), 7.86(\mathrm{~d}, 1 \mathrm{H}), 8.03(\mathrm{~d}, 1 \mathrm{H}), 8.30(\mathrm{~d}, 1 \mathrm{H}), 8.45(\mathrm{~s}$, 4H), 8.70-8.80 (m, 6H). FT/IR (KBr, cm $\left.{ }^{-1}\right)$ : 2233 (CN), 1781, $1723\left(\mathrm{C}=\mathrm{O}\right.$ in imide), 1371, $730(\mathrm{C}-\mathrm{N}), 1515,1340\left(\mathrm{NO}_{2}\right)$, 2922, $2957\left(\mathrm{CH}_{2}\right)$. UV-vis (NMP): $\lambda_{\max }=298,528 \mathrm{~nm}$ $\left(\varepsilon_{528}=2.37 \times 10^{4} \mathrm{Lmol}^{-1} \mathrm{~cm}^{-1}\right)$.

PI-4a: ${ }^{1} \mathrm{H}$ NMR (DMSO- $d_{6}, \delta$, ppm): 2.01 (s, $\left.\mathrm{CH}_{3}, 24 \mathrm{H}\right), 3.33$ (t, $\left.\mathrm{CH}_{2}, 8 \mathrm{H}\right), 3.87\left(\mathrm{~s}, \mathrm{CH}_{2}, 4 \mathrm{H}\right), 4.51\left(\mathrm{t}, \mathrm{CH}_{2}, 8 \mathrm{H}\right), 6.59(\mathrm{t}, 1 \mathrm{H})$, $6.92(\mathrm{~d}, 4 \mathrm{H}), 7.12(\mathrm{t}, 4 \mathrm{H}), 7.78-7.90(\mathrm{~m}, 8 \mathrm{H}), 8.00(\mathrm{~s}, 8 \mathrm{H})$, 8.20-8.40 (m, 12H). FT/IR $\left(\mathrm{KBr}, \mathrm{cm}^{-1}\right): 1782,1722(\mathrm{C}=\mathrm{O}$ in imide), 1371, $730(\mathrm{C}-\mathrm{N}), 1515,1341\left(\mathrm{NO}_{2}\right), 2955,2921\left(\mathrm{CH}_{2}\right)$. UV-vis (NMP): $\lambda_{\max }=262,300,341,509 \mathrm{~nm}$.

PI-4b: ${ }^{1} \mathrm{H}$ NMR (DMSO- $\left.d_{6}, \delta, \mathrm{ppm}\right): 2.01$ (s, $\left.\mathrm{CH}_{3}, 24 \mathrm{H}\right), 3.34$ (t, $\left.\mathrm{CH}_{2}, 8 \mathrm{H}\right), 3.87$ (s, $\left.\mathrm{CH}_{2}, 4 \mathrm{H}\right), 4.52$ (t, $\left.\mathrm{CH}_{2}, 8 \mathrm{H}\right), 6.59$ (t, $\left.1 \mathrm{H}\right)$, $6.92(\mathrm{~d}, 4 \mathrm{H}), 7.13(\mathrm{t}, 4 \mathrm{H}), 7.80-7.90(\mathrm{~m}, 8 \mathrm{H}), 8.00(\mathrm{~s}, 8 \mathrm{H})$, $8.20-8.50(\mathrm{~m}, 12 \mathrm{H})$. FT/IR $\left(\mathrm{KBr}, \mathrm{cm}^{-1}\right): 1782,1722(\mathrm{C}=\mathrm{O}$ in imide), 1370, $733(\mathrm{C}-\mathrm{N}), 1514,1340\left(\mathrm{NO}_{2}\right), 2958,2924\left(\mathrm{CH}_{2}\right)$. UV-vis (NMP): $\lambda_{\max }=263,300,341,510 \mathrm{~nm}$.

\section{Polymer Film Preparation}

The homogeneous solutions of polymers (P1-P4) in NMP were filtered through $0.2 \mu \mathrm{m}$ membranes and casted onto glass substrates. Residual solvent was removed from the films by heating for $2 \mathrm{~h}$ at $170-190{ }^{\circ} \mathrm{C}$ near the polymer $T_{\mathrm{g}}$; a temperature at which polymer segmental motion is large enough to free possibly trapped solvent molecules. Film thickness was determined with from the interferences of the optical transmittance and reflectance spectra.

\section{Characterization}

FT/IR spectra were recorded on a BIO-RAD FTS 40 A Spectrometer using $\mathrm{KBr}$ pellets. ${ }^{1} \mathrm{H}$ NMR spectroscopy were carried out on a Varian 300 Spectrometer using DMSO- $d_{6}$ as solvent and TMS as the internal standard. UV-vis spectra were recorded in NMP solution of polymers and as films casted on glass using a Jasco V570 UV-V-NIR spectrometer. The X-rays diffraction patterns on solid samples were recorded using $\mathrm{CuK} \alpha$ radiation on a wide-angle $\mathrm{HZG}-4$ diffractometer working in the typical Bragg geometry. Number-average $\left(M_{\mathrm{n}}\right)$ and weight-average $\left(M_{\mathrm{w}}\right)$ molecular weight were determined by SEC experiments with tetrahydrofuran (THF, $35^{\circ} \mathrm{C}, 1 \mathrm{~mL} /$ min), using a set of two PLgel $5 \mu \mathrm{m}$ MIXED-C ultrahigh efficiency columns. Isocratic pump Spectra Physics 8800 as a solvent delivery system, differential refractive index detector (VE3580, Viscotek), viscometer detector (270 Dual Detector Array, viscometer only, Viscotek) were applied. Polystyrene 
was used as the standard. Differential scanning calorimetry (DSC) measurements were done using a Du Pont 1090B apparatus with a heating rate of $20^{\circ} \mathrm{C} / \mathrm{min}$ under nitrogen. Thermogravimetric analyses (TGA) were performed on a Paulik-Erdey apparatus at a heating rate of $10^{\circ} \mathrm{C} / \mathrm{min}$ under nitrogen. The reduced viscosity was measured in NMP (concentration $=0.2 \mathrm{~g} / 100 \mathrm{~mL}$ ) at $25^{\circ} \mathrm{C}$ using Ubbelohde viscometer. The measurements of two-photon absorption coefficient were performed using Z-scan technique at peak wavelength $\lambda=800 \mathrm{~nm}$ from femtosecond titanium:sapphire (Ti:sapphire) regenerative amplifier (pulse $=100 \mathrm{fs}$, pulse intensity of $\mathrm{I}_{0}=7.95 \times 10^{15} \mathrm{~W} / \mathrm{m}^{2}$ at the focus).

\section{RESULT AND DISCUSSION}

In this work, poly(esterimide)s with azobenzene units which consist of one azo or two azo bonds and one nitro or two nitro or nitro and cyano substituted phenyl group were synthesized. Polymers differing in the degree of functionalization with azobenzene moieties as well. Polymer properties were investigated from a two points of view: the effect of kind of substituents on azobenzene groups and the chromophore concentration in the polymer chain.

In the first stage of this work azobenzene chromophores were prepared to estimate the degree of functionalization of the precursor poly(esterimide) (PI) with azobenzene compounds. Chemical structures and synthetic approach for the chromophores are illustrated in Figure 1. The chromophores AZ-2AZ-4 are new compounds, while, the chromophore AZ-1 was described in the literature. ${ }^{30}$

The amines (4-nitroaniline for AZ-1, 2,4-dinitroaniline for AZ-2, 2-cyan-4-nitroaniline for AZ-3, Disperse Orange 3 for AZ-4) were converted to the corresponding diazonium salts, which were subjected to coupling reactions with $\mathrm{N}, \mathrm{N}$-di-(2hydroxyethyl)aniline to give compounds of type $\mathbf{A Z}$.

\section{Polymer Synthesis and Characterization}

The precursor poly(esterimide) PI, i.e., without azobenzene

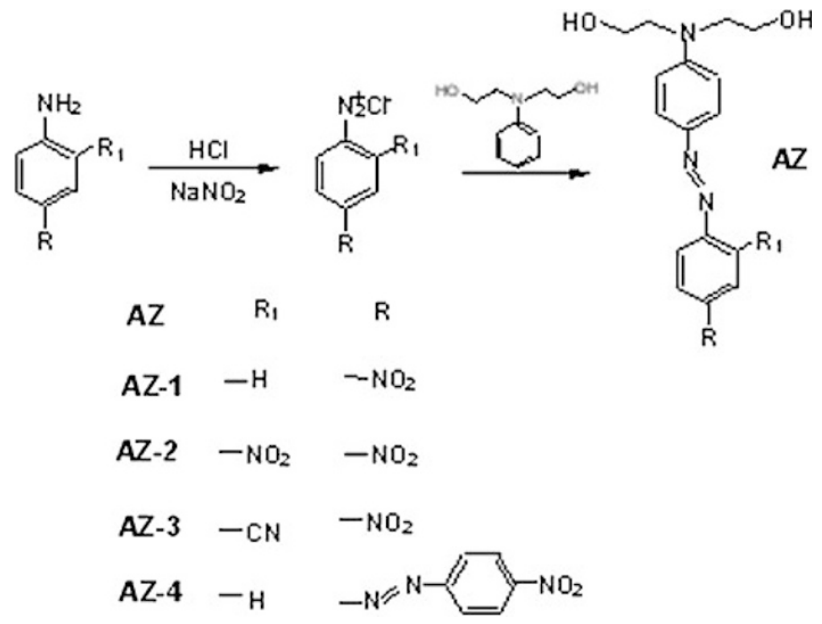

Figure 1. Chemical structures and synthesis of chromophores. group was obtained in different polycondesation conditions. Polycondesation conducted under the in situ silylation conditions, in the presence of CTMS and pyridine as catalyst resulted in polyimide with the highest value of viscosity $(0.35 \mathrm{dl} / \mathrm{g})$, indicating the highest molecular weight of polymer. Although the relation between viscosity and molecular weight can only be rigorously taken when the viscometric equation is known, we considered that this relation could be reasonably adapted in this case to compare the result for the same polymer. Polymer with the highest value of viscosity was the subject of this work, i.e., was functionalized by connecting various azo chromophores to main polymer chain through an azo-coupling reaction. The synthetic route and structures of the photochromic poly(esterimide)s obtained are shown in Figure 2.

The diazonium salt attacks the benzene ring pendant from the backbone at the position with higher electron density. The bulkiness of the attacking group and the resulting steric hindrance limit the electrophilic substitution exclusively at the para position. ${ }^{7}$

The ideal material for many end-use applications should be highly amorphous as the crystallites introduce unwanted light scattering. Thus, the crystallinity of the poly(esterimide)s films was evaluated by wide-angle X-ray diffraction experiments. $\mathrm{X}$-Ray patterns obtained from these measurements are shown in Figure 3.

One broad diffraction peak of diffusion type centered at 25 $\operatorname{deg}(2 \theta)$ was observed for all studied samples ( $c f$. Figure 3 ). All the polymers showed the same diffraction patterns typical for perfectly amorphous materials.

Instrumental techniques including FT/IR and ${ }^{1} \mathrm{H}$ NMR spectroscopies were performed for characterization of the polymer molecular structure. Figure 4 shows FT/IR spectra of the parent poly(esterimide) PI and two azobenzene functionalized polymers PI-1 and PI-3.

The clear appearance of the characteristic absorption bands of the nitro group at 1515 and $1340 \mathrm{~cm}^{-1}$ in the spectra of PI1-PI-4 indicates the introduction of NLO chromophores into the backbone of the precursor PI.

The incorporation of chromophores into the polymer PI was also monitored by ${ }^{1} \mathrm{H}$ NMR spectra. Figure 5. presents the ${ }^{1} \mathrm{H}$ NMR spectra of the precursor PI and polymer PI-1a in which the chromophore loading level was $100 \%$.

All the peaks in ${ }^{1} \mathrm{H}$ NMR spectrum were assigned to the hydrogen atoms of the recurring unit. In the ${ }^{1} \mathrm{H}$ NMR spectrum of the precursor PI registered in room temperature the protons of methylene group linked with a tertiary amine and methylene group between phenyl rings gave one signal at $3.87 \mathrm{ppm}$ which splitted at $80^{\circ} \mathrm{C}$ on two peaks one at 3.87 and second at $3.93 \mathrm{ppm}$ characteristic for aliphatic protons between aromatic rings ( $c f$. Figure 5(a)). The ${ }^{1} \mathrm{H}$ NMR spectrum of PI showed a strong signal at $6.60 \mathrm{ppm}$ ascribed to the proton in benzene ring in para position to amine group which was selected for observation of the functionalization reaction. As the post-azocoupling reaction proceeded this proton peak completely disappeared ( $c f$. Figure 5 PI-1a) indicated that diazo group 
<smiles>Cc1cc(Cc2cc(C)c(N)c(C)c2)cc(C)c1N</smiles>

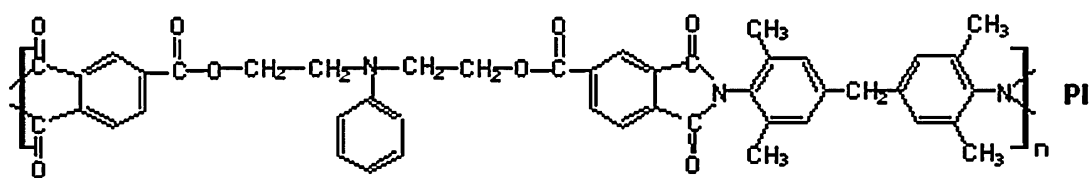<smiles>[R]c1ccc(N=NC(C)C)c(Br)c1</smiles>

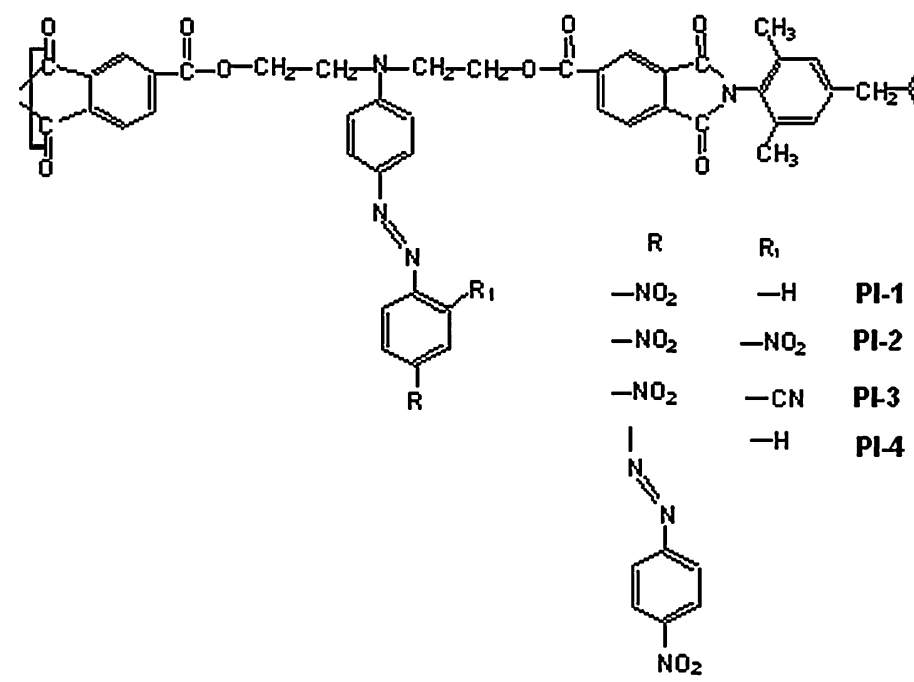

Figure 2. Reaction scheme of the poly(esterimide) synthesis and structures of synthesized azobenzene functionalized polymers PI-1-PI-4.

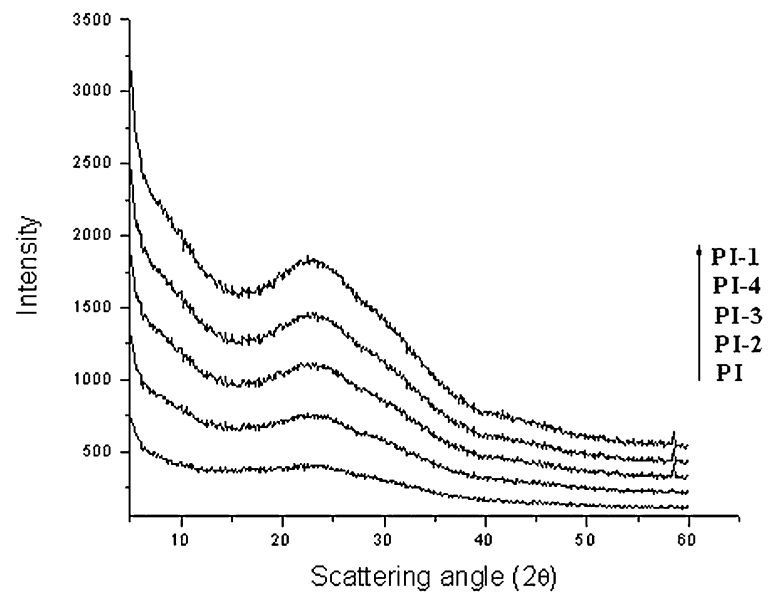

Figure 3. X-Ray diffraction patterns of the prepared poly(esterimide)s PI-1$\mathrm{PI}-4$

were attached at para position of the benzene ring, and new peaks appeared at about $7.82 \mathrm{ppm}$ due to protons in benzene ring, ortho and meta position to $\mathrm{N}=\mathrm{N}$ group. Nevertheless, full substitution of the azobenzene group was not achieved in polymers PI-1b,c,d, PI-2a, PI-3a and PI-4a,b, as shown by the presence of $c a$. $6.60 \mathrm{ppm}$ peak ( $c f$. Figure 5).

In this study, the level of functionalization was determined by UV-vis spectroscopy using the Beer-Lambert law. ${ }^{37}$ The degree of chromophore substitution in the polymer was calculated from the calibration curves obtained from UV-vis spectra of the chromophore solutions with various concentration for each chromophore AZ. Figure 6 shows an exemplary calibration curve for the chromophore AZ-2.

With this method it appeared that the amount of azobenzene group in final polymers was approximately in the range of 6 $100 \%$ ( $c f$. Table I). Various conditions of the post-azo coupling reaction which were applied let to obtained polymers with various content of the azobenzene group due to the chromophore concentration effect on properties could be studied.

The solubility of the synthesized poly(etherimide)s was determined (by visual observation) for the powdered samples using excess of various solvents. These results with the chromophore loading level and molecular weights of some polymers are listed in Table I. 


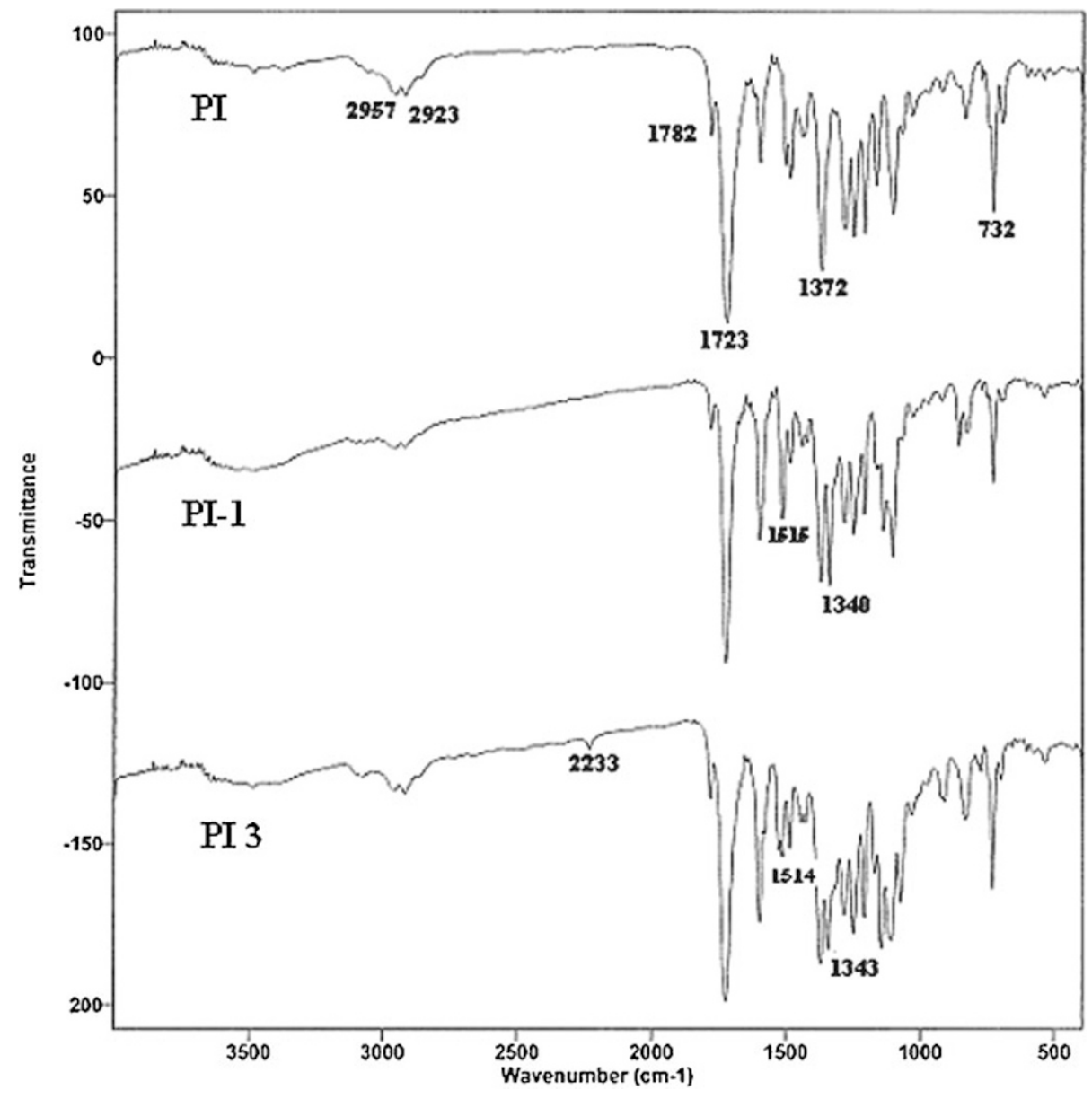

Figure 4. FT/IR spectra of exemplary poly(esterimide)s PI-1 and PI-3 and their precursor poly(esterimide) PI.

It was observed that all polymers were soluble not only in strong polar organic solvents but also in tetrahydrofuran (THF) and in chloroform. Some of them were partially soluble in acetonitryle. The good solubility of these polymers resulted from the presence of both the ester and aliphatic groups in a polymer chain. The influence of kind of substituent in azobenzene moiety on the polymer solubility was observed. Polymers functionalized with azobenzene containing as substituent one nitro group, i.e., PI-1 and PI-4 showed better solubility than the others. The presence of both nitro and cyano groups in azobenzene moiety decreased the solubility of polymers (PI-3 and PI-4). The molecular weight of polymers was determined using size exclusion chromatography (SEC). In any case these values have to be taken as indicative only, since calibration with polystyrene may result in questionable results when the polymers different strongly from polystyrene.

\section{Thermal Behavior of Photochromic Poly(esterimide)s}

Thermal properties of the prepared poly(esterimide)s were examined by differential scanning calorimetry (DSC) and theromgravimetric analysis (TGA). The glass transition temperature of the polymers $\left(T_{\mathrm{g}}\right)$ and their thermal stabilities are summarized in Table II.
Thermal properties of the poly(esterimide)s can be discussed in terms of functionalization degree of the polymers along with the kind of substituents on azobenzene units. The glass transition temperatures, defined by the midpoint of the base line shift of the polymers, were observed in the range of 159$224^{\circ} \mathrm{C}$. The glass transition temperatures of the functionalized polymers were higher than this of the precursor polymer PI (except for PI-4b). Polymers containing azobenzene groups with two substituents $\mathrm{CN}$ and $\mathrm{NO}_{2}$, i.e., PI-3 exhibited higher value of $T_{\mathrm{g}}$ than others. It was found that the chromophore concentration also affected the $T_{\mathrm{g}}$ values. The incorporation of chromophore moieties into polymers increased their glass transition temperature. However, the polymers with higher chromophore concentration revealed the lower $T_{\mathrm{g}}$ value in comparison with the polymers with low degree of functionalization.

Thermal stability of the precursor polymer PI and polymers with the highest chromophore concentration was investigated. The poly(esterimide)s exhibited a similar TGA pattern in which decomposition proceeded through two steps. The first one might be related to the loss of a NLO chromophore, the second one might be related to the polymer backbone. These polymers did not show obvious weight loss before the scanning 

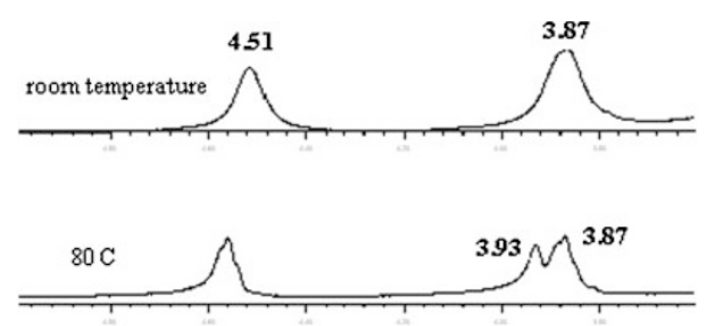

(a)

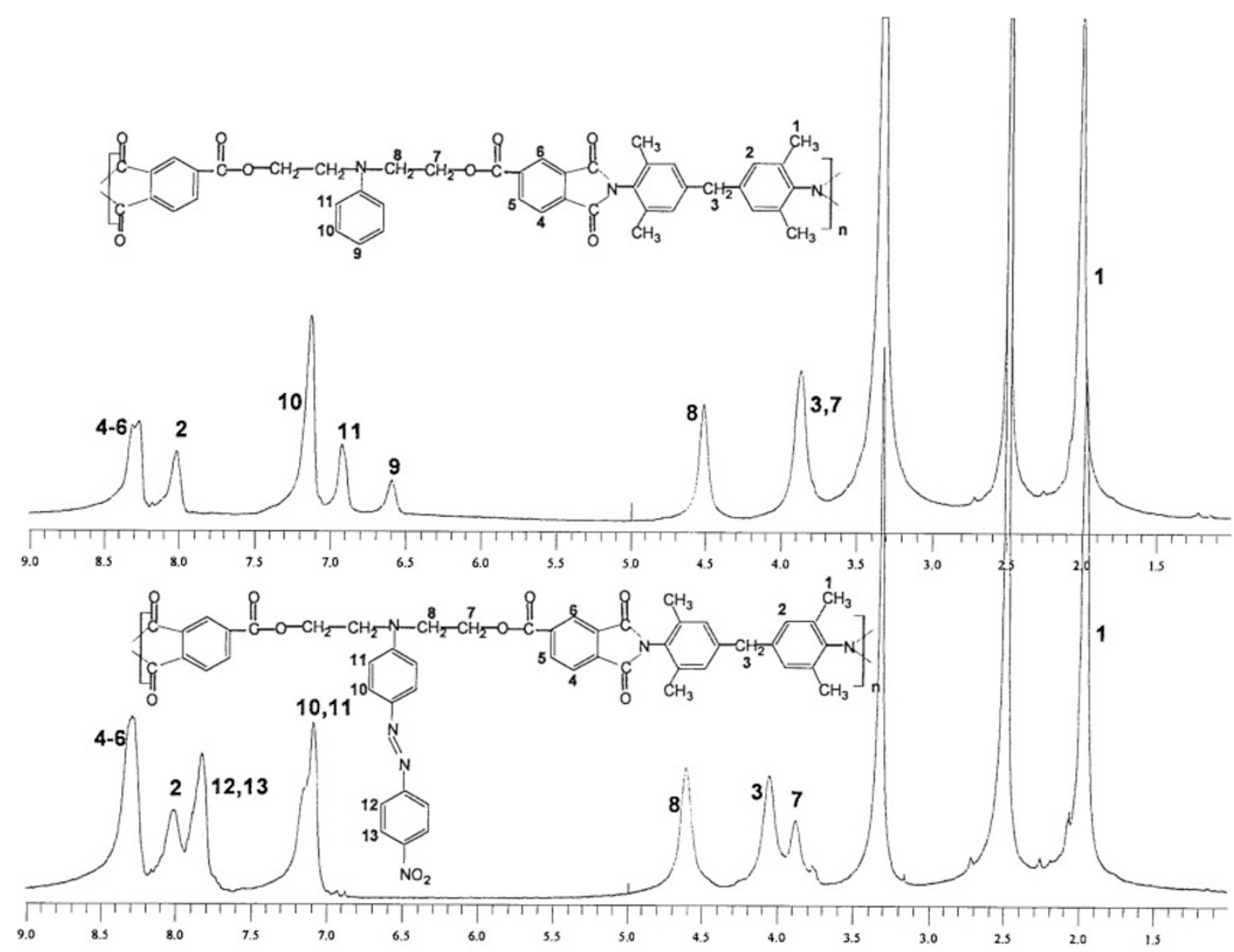

(b)

Figure 5. ${ }^{1} \mathrm{H}$ NMR spectra of poly(etherimide)s $\mathrm{PI}$ at room temperature and at $80^{\circ} \mathrm{C}$ in the range from $5-3.5 \mathrm{ppm}$ (a) and full spectra of poly(etherimide)s $\mathrm{PI}$ and PI-1a.

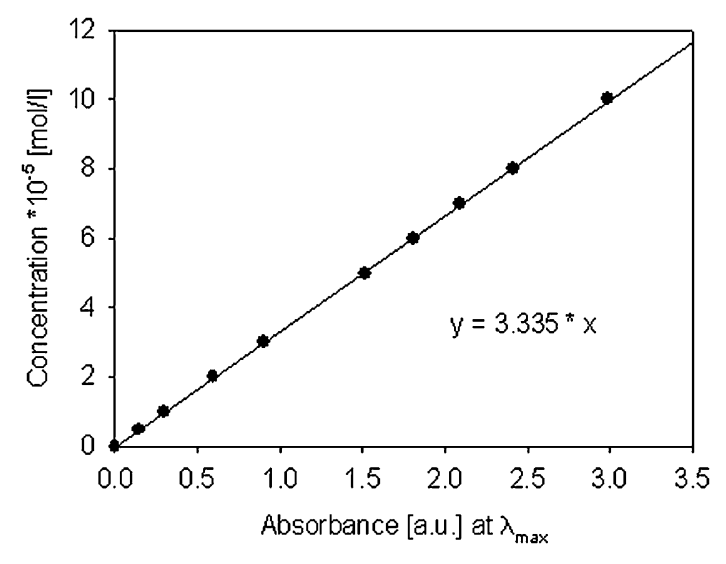

Figure 6. Calibration curve for the chromophore AZ-2. temperature reached up to $250{ }^{\circ} \mathrm{C}$ implying that no thermal decomposition occurred and the onset decomposition temperatures were as high as above $300^{\circ} \mathrm{C}$. The decomposition temperature $\left(T_{\mathrm{d}}\right)$ (based on $5 \%$ weight loss) and $10 \%$ weight loss temperatures $\left(T_{\mathrm{d}}\right.$ and $\left.T_{10}\right)$, which were usually considered as the criterion in determining the thermal stability of high temperature polymers, were in range of $311-334{ }^{\circ} \mathrm{C}$ and $344-$ $410^{\circ} \mathrm{C}$ of chromophore functionalized polymers, respectively, whereas the precursor PI exhibited $T_{\mathrm{d}}$ at $393{ }^{\circ} \mathrm{C}$. Furthermore, the residual weight at $800^{\circ} \mathrm{C}$ in nitrogen of chromophore containing polymers was in the range of $48-58 \%$. The introduction of azobenzene group into polymer chain on the one hand resulted in decreasing the value of $T_{\mathrm{d}}$, but on the other hand increased the char yield at $800{ }^{\circ} \mathrm{C}$. 
Table I. The chromophore loading level in the poly(esterimide)s their solubility and SEC characterization

\begin{tabular}{|c|c|c|c|c|c|c|c|c|c|c|}
\hline \multirow{2}{*}{ Polymer } & \multirow{2}{*}{$\begin{array}{l}\text { Chromo- } \\
\text { phore } \\
\text { loading } \\
\text { level }\end{array}$} & \multicolumn{3}{|c|}{ SEC (kDa eq. PS) } & \multicolumn{6}{|c|}{ Solubility } \\
\hline & & $M_{\mathrm{n}}$ & $M_{\mathrm{w}}$ & $\mathrm{PDI}^{\mathrm{a}}$ & NMP & DMA & DMSO & THF & $\mathrm{CHCl}_{3}$ & $\mathrm{CH}_{3} \mathrm{CN}$ \\
\hline PI & $0 \%$ & 8.5 & 14.0 & 1.8 & + & + & + & + & + & - \\
\hline PI-1a & $100 \%$ & 5.0 & 22.0 & 4.4 & + & + & + & + & + & \pm \\
\hline PI-1b & $6 \%$ & 7 & 19 & 2.7 & + & + & + & + & + & \pm \\
\hline Pl-1c & $15 \%$ & $-^{b}$ & $-^{b}$ & $-^{b}$ & + & + & + & + & + & \pm \\
\hline PI-1d & $33 \%$ & 3.0 & 16.0 & 5.3 & + & + & + & + & + & \pm \\
\hline $\mathrm{PI}-2 \mathrm{a}$ & $51 \%$ & $-^{\mathrm{b}}$ & $-{ }^{\mathrm{b}}$ & $-^{\mathrm{b}}$ & + & + & + & ++ & ++ & - \\
\hline $\mathrm{PI}-2 \mathrm{~b}$ & $100 \%$ & $-^{\mathrm{b}}$ & $-^{b}$ & $-^{\mathrm{b}}$ & + & + & + & ++ & ++ & - \\
\hline PI-3a & $49 \%$ & 6 & 18 & 2.9 & + & + & + & + & + & \pm \\
\hline PI-3b & $100 \%$ & $-^{\mathrm{b}}$ & $-^{\mathrm{b}}$ & $-^{\mathrm{b}}$ & + & + & + & + & + & \pm \\
\hline $\mathrm{PI}-4 \mathrm{a}$ & $27 \%$ & 4 & 26 & 6.4 & + & + & + & + & + & \pm \\
\hline $\mathrm{PI}-4 \mathrm{~b}$ & $42 \%$ & $-{ }^{\mathrm{b}}$ & $-{ }^{b}$ & $-{ }^{\mathrm{b}}$ & + & + & + & + & + & \pm \\
\hline
\end{tabular}

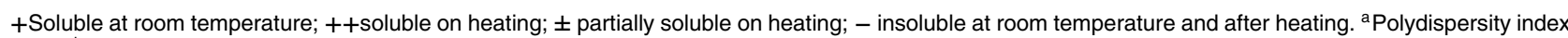
$M_{\mathrm{w}} / M_{\mathrm{n}}$. ${ }^{\mathrm{b}}$ Not measured.

Table II. Thermal properties of the poly(esterimide)s

\begin{tabular}{cccccc}
\hline \multirow{2}{*}{ Polymer } & $\begin{array}{c}T_{\mathrm{g}} \\
{\left[{ }^{\circ} \mathrm{C}\right]}\end{array}$ & \multicolumn{5}{c}{$\mathrm{TGA}$} \\
\cline { 3 - 6 } & & $T_{\mathrm{d}}{ }^{\mathrm{a}}\left[{ }^{\circ} \mathrm{C}\right]$ & $T_{10}{ }^{\mathrm{b}}\left[{ }^{\circ} \mathrm{C}\right]$ & $T_{20}{ }^{\mathrm{c}}\left[{ }^{\circ} \mathrm{C}\right]$ & Char yield $^{\mathrm{d}}[\%]$ \\
\hline PI & 177 & 393 & 405 & 432 & 30 \\
PI-1a & 179 & 326 & 351 & 494 & 52 \\
PI-1c & 184 & - & - & - & - \\
PI-1d & 213 & - & - & - & - \\
PI-2a & 201 & - & - & - & 53 \\
PI-2b & 176 & 311 & 363 & 500 & - \\
PI-3a & 224 & - & - & - & 58 \\
PI-3b & 216 & 334 & 410 & 531 & - \\
PI-4a & 191 & - & - & - & 48 \\
PI-4b & 159 & 311 & 344 & 463 & - \\
\hline
\end{tabular}

a Decomposition temperature, determined by TGA in nitrogen, based on $5 \%$ weight loss. ${ }^{\text {b }}$ Temperature of $10 \%$ weight loss. ${ }^{\mathrm{c}}$ Temperature of $20 \%$ weight loss. ${ }^{\mathrm{d}}$ Residual weight at $800^{\circ} \mathrm{C}$ in nitrogen.

\section{Linear Optical Properties}

UV-vis spectra of poly(etherimide)s were acquired both in NMP solution and in polymer films on a glass. The range of UV-vis measurements was limited by transparency of the used solvent and substrate. The representative one-photon absorption spectra of PI and functionalized polymers are compared in Figure 7.

Absorption spectra of the studied azopolymers show similar characteristics, i.e., a strong peak with a maximum located at the range of $470-530 \mathrm{~nm}$ attributed to the electronic transition moment of trans-azo chromophore which was separated clearly from the absorption in the UV region in the range of 263$300 \mathrm{~nm}$ which is characteristic to transition within the polymer backbone. The chromophores showed the spectroscopic characteristics of the donor-acceptor type azo compounds (i.e., pseudo-stlibene type azo chromophores), in which the highintensity $\pi-\pi^{*}$ absorption band appears at long wavelength in visible region. ${ }^{38}$ PI exhibited no absorption above $350 \mathrm{~nm}$. The $\lambda_{\max }$ values of the $\pi-\pi^{*}$ transition of azobenzene in the chromophores and azofunctionalized polymers in NMP solution and in form of films are collected in Table III.

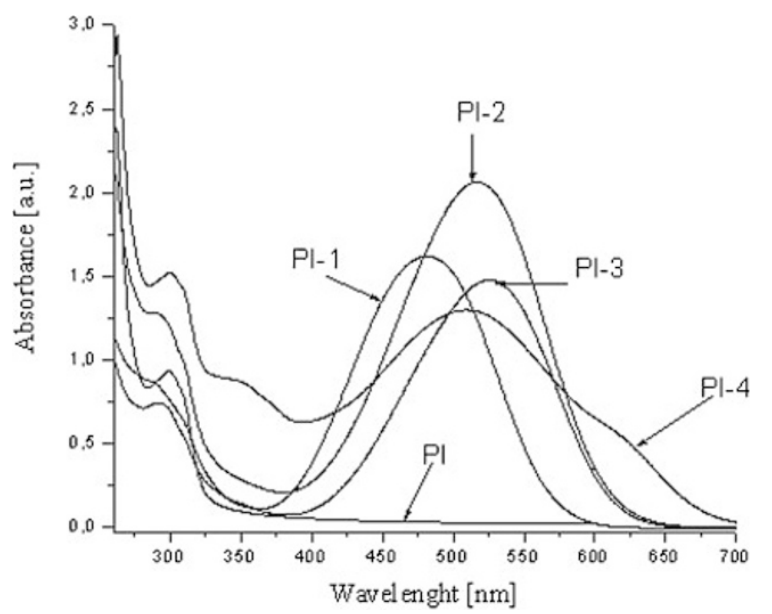

Figure 7. UV-Vis spectra of the polymer PI before and after substitution PI-1-PI-4.

Positions of azobenzene absorption band of the polymers were changed as compared to that of the $\mathbf{A Z}$ compounds. Blue shift (about $22 \mathrm{~nm}$ ) of $\pi-\pi^{*}$ transition of azobenzene between poly(esterimide)s and the chromophores $\mathbf{A Z}$ was observed. The $\lambda_{\max } \mathrm{s}$ are strongly affected by substituents on the azobenzene unit. The polymers containing azobenzene with two substituents, i.e., cyano and nitro (PI-3) revealed a peak maximum of the $\pi-\pi^{*}$ absorption band shifted batochromically in comparison with the compounds containing others substituents (PI-1, PI-2 and PI-4). The presence of one nitro group in azobenzene unit shifted hipsochromically the absorption maximum compared to others.

The absorption maximum in the polymer film was shifted to shorter wavelength in comparison to that in solution (about 17$28 \mathrm{~nm}$ ), indicating H-type aggregation of azobenzene chromophores in the film, similarly to what was observed for others azopolymers. ${ }^{10,39}$ The polymer films exhibited similar energy gap $\left(\mathrm{E}_{\mathrm{G}}\right)(c f$. Table III) which was deduced from the linear 
Table III. $\pi-\pi^{*}$ transition of azobenzene group in the poly(esterimide)s both in NMP solution and in films as deposited on glass slides and the chromophores AZ in NMP solution. The energy gap and thickness of the polymer films

\begin{tabular}{|c|c|c|c|c|}
\hline \multirow{2}{*}{$\begin{array}{c}\text { Polymer } \\
\text { AZ }\end{array}$} & \multicolumn{2}{|c|}{$\lambda_{\max }[\mathrm{nm}](\mathrm{eV})$} & \multirow{2}{*}{$\mathrm{E}_{\mathrm{G}}{ }^{*}[\mathrm{eV}]$} & \multirow{2}{*}{$d^{* *}[\mu \mathrm{m}]$} \\
\hline & in NMP & in film & & \\
\hline PI-1 & $484(2.56)$ & $456(2.72)$ & 2.05 & $\begin{array}{l}2.59 \text { (PI-1a), } 3.56 \text { (PI-1b) } \\
1.96 \text { (PI-1c), } 1.61 \text { (PI-1d) }\end{array}$ \\
\hline AZ-1 & $509(2.44)$ & - & - & - \\
\hline $\mathrm{PI}-2$ & $517(2.40)$ & $500(2.48)$ & 1.90 & 1.55 (PI-2a), 0.53 (PI-2b) \\
\hline AZ-2 & $535(2.32)$ & - & - & - \\
\hline PI-3 & $528(2.35)$ & $504(2.46)$ & 1.89 & 1.22 (PI-3a), 3.25 (PI-3b) \\
\hline AZ-3 & $548(2.26)$ & - & - & - \\
\hline $\mathrm{PI}-4$ & $510(2.44)$ & $480(2.58)$ & 1.91 & 1.58 (PI-4a), 1.00 (PI-4b) \\
\hline AZ-4 & $530(2.34)$ & - & - & - \\
\hline
\end{tabular}

$\mathrm{E}_{\mathrm{G}}{ }^{*}( \pm 0.02 \mathrm{eV})$ - Energy gap of the polymer films $d^{* *}$-Film thickness

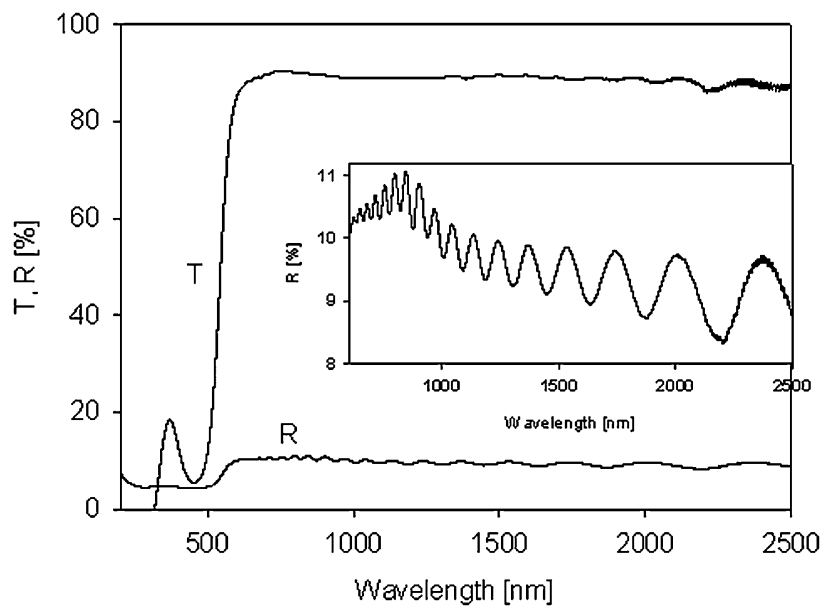

Figure 8. Transmission and reflectivity spectra of PI-1b film; thickness interferences are shown detailed on part of the reflectivity curve.

approximation of $(\alpha \cdot E)^{1 / 2}=f(E)$ dependence (known as Tauc relation). ${ }^{40,41}$

The film thickness $(d)$ was determined from the interferences of optical spectra, as it is seen in Figure 8

The following formula was used for calculation of the film thickness:

$$
\begin{aligned}
d & =\frac{1}{2 \sqrt{n^{2}-\sin ^{2} \phi}} \cdot \frac{\lambda_{1} \cdot \lambda_{2}}{\lambda_{1}-\lambda_{2}} \cdot \frac{p}{1000} \\
& =\frac{1}{2 \sqrt{n^{2}-\sin ^{2} \phi}} \cdot \frac{p}{r_{1}-r_{2}} \cdot 10^{4}[\mu \mathrm{m}],
\end{aligned}
$$

where: $\lambda_{1}, \lambda_{2}$-peak wavelength [nm] (both peaks or valleys); $r_{1}, r_{2}$-number of peak wavelength $\left[\mathrm{cm}^{-1}\right] ; p$-number of interference waves between $\lambda_{1}$, and $\lambda_{2} ; \phi$-angle of light beam (for transmission measurements $\phi=0 \mathrm{deg}$, for reflection $\phi$ depend on reflectivity attachment). The determined polymer film thickness were in the range of $0.53-3.56 \mu \mathrm{m}$ ( $c f$. Table III).

\section{Nonlinear Optical Properties}

The characterization of the nonlinear properties of polymers was carried out with the femtosecond Z-scan technique. The

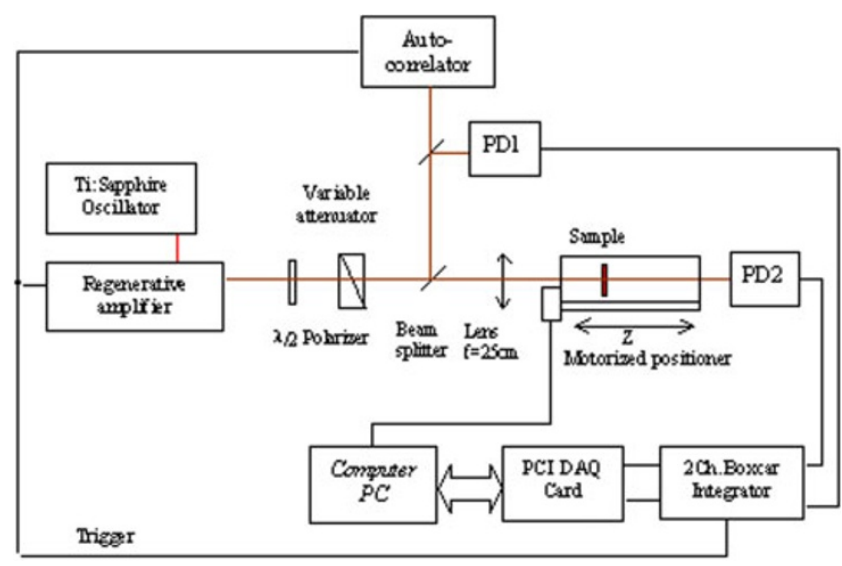

Figure 9. TPA experimental setup.

two-photon absorption coefficient of these polymers was measured at $800 \mathrm{~nm}$, which is a nonresonant condition for the compounds investigated. All compounds studied in this work display absorption bands in the range between 260 and $600 \mathrm{~nm}$, being transparent in the near infrared region as can be seen in Figure 7. Accordingly, nonlinear optical measurements were made under nonresonant excitation. For TPA measurement well know open aperture Z-scan method has been used. ${ }^{42}$ The experimental set up is presented in Figure 9.

Tight beam profile has been obtained using long focal length lens $(\mathrm{f}=25 \mathrm{~cm}$ ). Sample was moved from position before beam waist to position after it. During this movement beam intensity increases to reach maximal value in focus and then decreases after passing focal plane. The transmittance (PD1/ PD2, $c f$. Figure 9) was simultaneously recorded by mean of two amplified photodiodes and dual channel boxcar integrator synchronized with data acquisition system and motorized translation stage.

In theory, the normalized transmittance for the open aperture zscan can be written as. ${ }^{42,43}$

$$
T(z)=\frac{1}{\sqrt{\pi} q_{0}(z)} \int_{-\infty}^{\infty} \ln \left[1+q_{0}(z) \exp \left(-\tau^{2}\right)\right] d \tau
$$

where $q_{0}(z)$ is in ratio with the two-photon absorption coefficient $(\beta) \quad\left(q_{0}(z)=\beta I_{0}(t) L_{\text {eff }} /\left(1+z^{2} / z_{0}^{2}\right)\right), \quad \mathrm{I}_{0}(\mathrm{t})$ is the intensity of laser beam at focus $(z=0), L_{\text {eff }} L_{\text {eff }}=[1-$ $\exp \left(-\alpha_{0} L\right] / \alpha_{0}$ is the effective thickness with $\alpha_{0}$ being the linear absorption coefficient and $L$ the sample thickness, $z$ is the sample position, and $\mathrm{z}_{0}$ is the diffraction length of the beam. In this work the open aperture Z-scan experiments have been performed with laser pulses at $800 \mathrm{~nm}$ from Ti:Sapphire regenerative amplifier with $100 \mathrm{fs}$ pulse duration, operating at $250 \mathrm{~Hz}$ repetition rate. For investigated thin polymer films pulse energy of $1.5 \mu \mathrm{J}$ was applied to obtain perceptible transmittance changes. This relatively high value is still far away from white light continuum generation, and undesired higher order nonlinearities. ${ }^{43}$ Attenuated pulse energy at front of the sample was measured by mean of pyroelectric energy meter. 


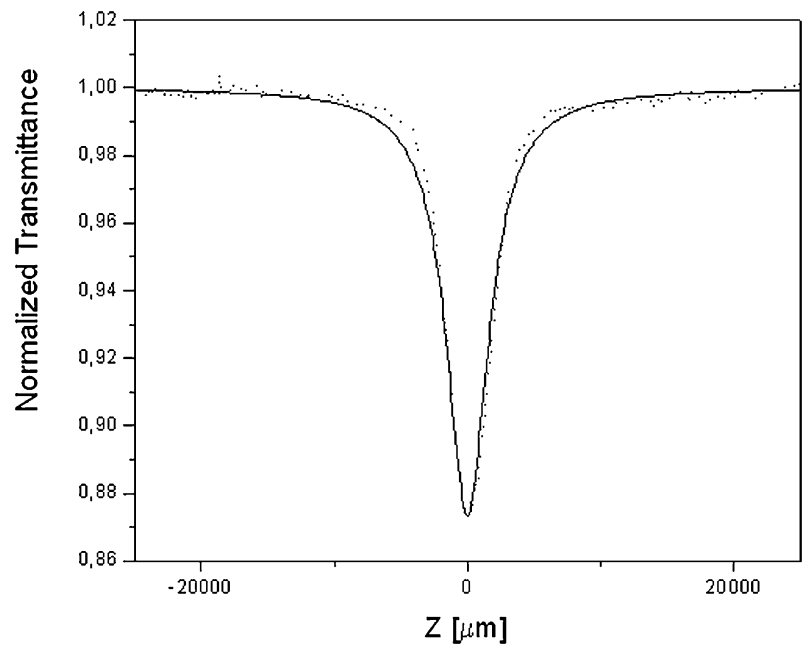

Figure 10. Z-scan data of open aperture, the trace of sample P1-1a: (dotted line) experimental data, (solid line) theoretical curve.

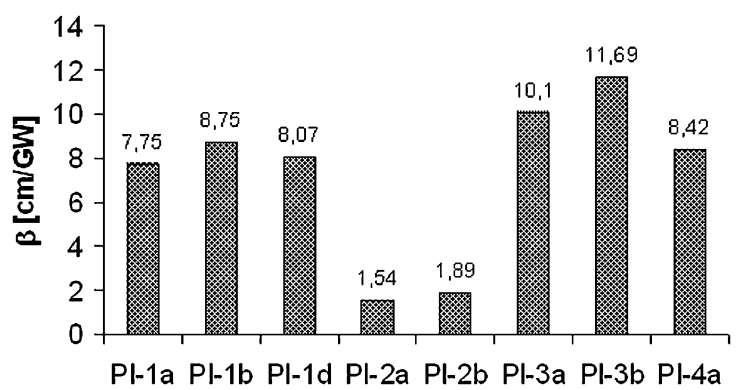

Figure 11. The values of TPA coefficient $\beta$ calculated for investigated azobenzene functionalized poly(esterimie)s.

Figure 10 shows the open aperture Z-scan normalized transmittance plotted as a function of the sample position $(z)$ measured for the polymer PI-1a.

An absorption peak in the normalized transmittance indicates the nonlinear absorption in polymers. The dotted line in Figure 10 represents the experimental data and the solid line presents the theoretical fitting obtained according to eq 2 . Thus, the two-photon coefficient $\beta$ was estimated in investigated polymer films and the results are collected in Figure 11.

It can be seen that the polymers significantly differing in magnitude of the two-photon absorption coefficient $\beta$. It has been found that molecules with high dipole moment should display the highest $\beta$ value. ${ }^{43}$ Similar tendency was observed in investigated polymers with one exception i.e. polymer PI-2. Taking onto account the dipole moment calculated for chromophores AZ with the James J. P. Stewart's MOPAC2007 8.032W program (AZ-1 $\mu=6.1 \mathrm{D}, \mathbf{A Z - 2} \mu=6.4 \mathrm{D}, \mathbf{A Z}-3$ $\mu=8.0 \mathrm{D})$ the $\beta$ of polymer PI-2 was expected to be higher than $\beta$ of PI-1, but was much lower in this experiment. The highest value of $\beta$ was detected for polymer possessing both nitro and cyano substituents on azobenzene moiety (PI-3). These groups acts as a stronger acceptor than one nitro group and caused an efficient charge transfer from the amino group (donor), located in the polymer backbone. A higher conjuga- tion path-by obtained by adding an extra azo group and phenyl ring (PI-4b) did not cause the $\beta$ to increased. Although this polymer contained chromophore with a higher $\pi$-electron bridge length, $\beta$ value was similar as for polymer with one azo bond PI-1d containing similar chromophore level. It seems that the most important factor for achieving high $\beta$ is the type of acceptor group than the $\pi$-electron bridge. The concentration of chromophore slightly influenced on $\beta$ value in investigated polymers.

A direct comparison of obtained $\beta$ value with reported for other polymers containing covalently bonded azobenzene units is not possible because TPA coefficient have been calculated only for polymer solutions. Exemplary the film prepared from DANS side-chain polymer exhibited $\beta=5.5 \mathrm{~cm} / \mathrm{GW}$ at $920 \mathrm{~nm} .{ }^{18}$

\section{CONCLUSIONS}

In conclusion, the new soluble poly(esterimide)s containing a push-pull type azobenzene moiety as a side group were synthesized and characterized. Chromophore functionalized polymers exhibited good thermal stability with high $T_{\mathrm{g}}$ and very good solubility. The preliminary results of two-photon absorption coefficient measurements were presented. Z-scan measurements indicated that the highest value of TPA coefficient (about $10 \mathrm{~cm} / \mathrm{GW}$ ) possessed polymer with both nitro and cyano group in azobenzene units. The first time, in this article TPA coefficient of azopoly(esterimide) films was reported.

Acknowledgment. The authors would like to thank Dr. H. Janeczek for DSC measurements, and Msc. M. Kawalec for SEC measurements.

Received: March 27, 2008

Accepted: May 16, 2008

Published: July 16, 2008

\section{REFERENCES}

1. D. R. Kanis, M. A. Ratner, and T. J. Marks, Chem. Rev., 94, 195 (1994).

2. T. C. Lin, S. J. Chung, K. S. Kim, X. P. Wang, G. S. He, J. Swiatkiewica, H. E. Pudavar, P. N. Prasad, and K. S. Lee, in "Advances in Polymer Science," Springer, Berlin, 2003, vol. 161, p 157.

3. H. J. Lee, J. Sohn, J. Hwang, and S. Y. Park, Chem. Mater., 16, 456 (2004).

4. T. Baldacchini, C. N. LaFratta, R. A. Farrer, M. C. Teich, B. E. A. Saleh, M. J. Naughton, and J. T. Fourkas, J. Apply. Phys., 95, 6072 (2004).

5. Z. Sekkat, H. Ishitobi, and S. Kawata, Opt. Commun., 222, 269 (2003).

6. C. C. Corredor, Zh.-L. Huang, K. D. Belfied, A. R. Morales, and M. V. Bondar, Chem. Mater., 19, 5165 (2007).

7. B. R. Cho, K. H. Son, S. H. Lee, Y.-S. Song, Y.-K. Lee, S. G.-J. Jeon, J. H. Choi, H. Lee, and M. Cho, J. Am. Chem. Soc., 123, 10039 (2001).

8. Y.-G. Liu, Y. Sui, J. Yin, J. Gao, Z.-K. Zhu, D.-Y. Huang, and Z.-G. Wang, J. Appl. Polym. Sci., Part A, 76, 290 (2000).

9. S. K. Yesodha, Ch. K. S. Pillai, and N. Tsutsumi, Prog. Polym. Sci. 
Part A, 29, 45 (2004).

10. M. R. Cardoso, U. M. Neves, L. Misoguti, Zh. Ye, X. R. Bu, and C. R. Mendonca, Opt. Mater., 28, 1118 (2006).

11. M. Maeda, H. Ishitobi, Z. Sekkat, and S. Kawata, Appl. Phys. Lett., 85, 351 (2004).

12. L. Yang, G. Wang, J. Wang, G. Wang, and Z. Xu, Optik, 113, 189 (2002).

13. X. Yang, L. Hong, G. Ma, Ch. Li, H. Xing, Y. Xu, and E. Liang, Opt. Commun., 272, 521 (2007).

14. C. R. Mendonca, U. M. Neves, L. De Boni, A. A. Andrade, D. S. dos Santos Jr., F. J. Pavinatto, S. C. Zilio, L. Misoguti, and O. N. Oliveria Jr., Opt. Commun., 273, 435 (2007).

15. H. Ishitobi, Z. Sekkat, and S. Kawata, J. Chem. Phys., 125, 164718 (2006).

16. H. L. Hampsch, J. Yang, G. K. Wong, and J. M. Torkensol, Macromolecules, 21, 526 (1988).

17. M. Cha, W. E. Torruellas, G. I. Stegeman, W. H. G. Horsthuis, G. R. Mohlmann, and J. Meth, Appl. Phys. Lett., 65, 2648 (1994).

18. M. Samoc, A. Samoc, and B. Luther-Davies, Synth. Met., 109, 79 (2000).

19. J.-P. Yang, Chem. Phys. Lett., 243, 129 (1995).

20. F. Meng, J. Mi, Sh. Qian, K. Chen, and H. Tian, Polymer, 44, 6851 (2003).

21. X. Chen, J. Zhang, H. Zhang, Z. Jiang, G. Shi, Y. Li, and Y. Song, Dyes Pigm., 77, 223 (2008).

22. J. Y. Do, S. K. Park, J.-J. Ju, S. Park, and M.-H. Lee, Opt. Mater., 26, 223 (2004).

23. H. Saadeh, L. Wang, and L. Yu, Macromolecules, 33, 1570 (2000).

24. J. Luo, J. Qin, H. Kang, and Ch. Ye, Chem. Mater., 13, 927 (2001).

25. T.-A. Chen, A. K.-Y. Jen, and Y. Cai, Macromolecules, 29, 535 (1996).

26. W. N. Leng, Y. M. Zhou, Q. H. Xu, and J. Z. Liu, Polymer, 42, 7749 (2001).

27. Y.-G. Liu, Y. Sui, J. Yin, J. Gao, Z.-K. Zhu, D.-Y. Huang, and Z.-G. Wang, J. Appl. Polym. Sci., 76, 290 (2000).
28. E. Ortyl, S. Kucharski, and T. Gotszalk, Thin Solid Films, 479, 288 (2005).

29. E. Schab-Balcerzak, B. Sapich, J. Stumpe, A. Sobolweska, and A. Miniewicz, e-Polymers, 021 (2006).

30. M. Chen, L. R. Dalton, L. P. Yu, Y. Q. Shi, and W. H. Steier, Macromolecules, 25, 4032 (1992).

31. R. Janik, S. Kucharski, A. Kubańska, and B. Łyko, Polish J. Chem., 75, 242 (2001).

32. D. Sek, E. Schab-Balcerzak, and E. Grabiec, Polymer, 39, 7001 (1998).

33. Y.-G. Liu, Y. Sui, J. Yin, J. Gao, Z.-K. Zhu, D.-Y. Huang, and Z.-G. Wang, J. Appl. Polym. Sci., 76, 290 (2000).

34. A. K.-Y. Jen, K. J. Drost, V. P. Rao, Y. Cai, Y.-J. Liu, R. M. Mininni, J. T. Kenney, E. S. Binkley, S. R. Marder, L. R. Dalton, and Ch. Xu, Polym. Prepr., 35, 130 (1994).

35. D. M. Munoz, J. G. de la Campa, J. de Abajo, and A. E. Lozano, Macromolecules, 40, 8225 (2007).

36. I. Zhao, Z. Yuxia, Z. Jiayun, and S. Yuquan, Eur. Polym. J., 36, 2418 (2000).

37. E. Schab-Balcerzak and D. Sek, High Perform. Polym., 13, 45 (2001).

38. Y. He, J. Yin, P. Che, and X. Wang, Eur. Polym. J., 42, 292 (2006).

39. E. Schab-Balcerzak, B. Sapich, and J. Stumpe, Polymer, 46, 49 (2005).

J. Wang, W. F. Cao, J. H. Su, H. Tian, Y. H. Huang, and Z. R. Sun, Dyes Pigm., 57, 171 (2003).

40. B. Jarzabek, J. Weszka, M. Domański, J. Jurusik, and J. Cisowski, J. Non-Cryst. Solids, 354, 856 (2008).

41. B. Jarzabek, J. Weszka, A. Burian, and G. Pocztowski, Thin Solid Films, 279, 204 (1996).

42. M. Sheik-Bahae, M. Ieee, A. A. Said, T.-H. Wei, and D. J. Hagan, J. Quantum Electronics, 26, 760 (1990).

43. L. De Boni, J. J. Rodrigues Jr., D. S. dos Santos Jr., C. H. T. P. Silva, D. T. Balogh, O. N. Oliveira Jr., S. C. Zilio, L. Misoguti, and C. R. Mendonca, Chem. Phys. Lett., 361, 209 (2002). 